\title{
Alejandro Reyes - Vozes dos porões: a literatura periférica/marginal do Brasil
}

Rio de Janeiro: Aeroplano, 2013

Mário Augusto Medeiros da Silva ${ }^{1}$

Vozes dos porões: a literatura periférica/marginal do Brasil é a versão modificada da tese de doutoramento do autor (apresentada na Universidade de Berkeley em 2011), que explicita quantidade significativa de inquietações e questões sobre o tema, um dos assuntos mais importantes da história literária e social brasileira contemporânea - o debate sobre a periferia, os sujeitos sociais periféricos e sua enunciação política e cultural.

O livro se insere numa trajetória de estudos construída ao longo da última década, notadamente das ciências sociais, que tentam, não sem dificuldades, analisar e demonstrar o que pode haver de novo e importante na discussão sobre a periferia no Brasil, colocada pelo ângulo da literatura e da produção cultural por intelectuais orgânicos.

$O$ fato de sua mirada ser ainda mais estrangeira que a dos pesquisadores universitários brasileiros voltados para $\mathrm{o}$ assunto apresenta sua primeira boa contribuição: se quase todos concordam que a periferia não é apenas uma questão espacial e geográfica, Reyes demonstra que, enquanto ideia, a periferia ultrapassa também os limites nacionais. Nesse sentido, o que ocorre em El sótano de los olvidados, no México (de onde ele retira parte do título seu trabalho) tem muito a ver com as noites poéticas de um bar da periferia do Capão Redondo (Nascimento, 2012); as questões que envolvem os ativistas políticos e culturais são questões globais, na sua interpretação; representam, em diferentes partes do mundo, lutas sociais contra as formas e visões de mundo capitalistas, por si excludentes e destruidoras, historicamente.

Pôr em situação global um assunto visto geralmente como local não significa que o autor ignore as especificidades do tema no Brasil. Pelo contrário: ele, assim como outros autores, busca conectar a literatura marginal ou periférica (batizada assim no final dos anos 1990, começo do século XXI, quando o escritor Ferréz lançou Capão Pecado e organizou

\footnotetext{
${ }^{1}$ Doutor em sociologia e professor da Universidade Estadual de Campinas (Unicamp), Campinas, SP, Brasil. E-mail: mariomed@ unicamp.br
} 
autores em antologias em torno daquela ideia) com os diferentes aspectos da história social, política e cultural brasileira que, progressivamente coadunados, assumiram a forma das periferias urbanas e a imposição brutal de modos de vida subalternizantes a seus moradores.

Reyes não deixa seu leitor esquecer alguns pontos dessa história: a formação social, a colonização e o genocídio indígena, a escravização negra e uma abolição incompleta; a posição historicamente dependente de nossas elites face às nações ibéricas, igualmente orbitais e secundárias; a aceleração do capitalismo e sua dinâmica destrutiva, promovendo uma modernidade traidora de suas promessas (liberdade, igualdade, fraternidade, emancipação), revolução industrial acelerada, migrações forçadas do rural ao urbano, do Norte/Nordeste para o Sul Maravilha, metropolização precária.

Reyes recupera esses fatos; e, na condição de brasilianista, soa-lhe impossível compreender aspectos dessa história sem observar que somos também parte inventada da formação latino-americana. Destarte, apesar de termos nos tornado independentes em 1822 - antes das lutas anticoloniais asiáticas e africanas do século XX, mas atrasados em relação a nossos vizinhos imediatos -, precisaríamos ainda descolonizar boa parte de nosso pensamento social, político e cultural.

Assim entenderíamos que fazemos parte de e somos ressonantes a contextos geograficamente distantes, mas tão aproximáveis como Oaxaca, Chiapas, Quito, Caracas, Cidade do México, Tepito, Buenos Aires, Tibete, Luanda, Maputo, Délhi etc.: somos parte de uma longa história de exploração capitalista. Mas também de luta social insurgente, nos termos dos autores a que recorre, muitos deles marxistas e póscoloniais estadunidenses, indianos, mexicanos, franceses e pesquisadores brasileiros, com destaque para, entre outros, Mike Davis, José Rabasa e Gayatri Spivak.

Nessa forma de observar o problema, não se pode deixar de lembrar que foi Roberto Schwarz (2000 [1977]) quem escreveu, em As ideias fora de lugar, sobre as condições sociais de produção do escritor no Brasil um país periférico do capitalismo do século XIX, capaz de produzir Machado de Assis -, demonstrando assim que, sempre imprevisível, existe a história. E que também nosso romancista tem de se colocar em compasso com o tique-taque do mundo, lidando com as questões da história mundial para formar sua composição literária. Válida para a análise acerca de Machado, isso também foi suscitado como mesma 
senda a seguir para discussão da literatura periférica do final do século XX (Silva, 2013). E é o que Vozes dos porões faz com competência.

A literatura periférica brasileira é um desses imprevistos históricos. Surgida em meio ao desmonte neoliberal e pós-ditatorial dos anos 1990, nas condições inóspitas de bairros sempre associados ao vazio, à violência e à pobreza, no senso comum, foi capaz de pautar, coletivamente, questões contemporâneas do Brasil. Obras como Capão Pecado, Manual prático do ódio, Da cabula, O trem, Suburbano convicto etc. e saraus como os da Cooperifa, Elo da Corrente, Binho, entre outros, promovem uma ressignificação de sentidos e de visões de mundo $d a$ e para a periferia, dos e para os periféricos. E à sociedade circundante, que, obrigada a estar atenta aos fatos em ação, tem de se repensar.

Ainda assim, as ações coletivas empreendidas por aqueles escritores não se restringem aos seus cenários imediatos: para além de suas viagens pelo Brasil, também promovem intercâmbio de ideias e ações com ativistas e escritores internacionais: vale lembrar as viagens, em diferentes momentos, de escritores como Ferréz, Sérgio Vaz, Allan da Rosa, Rodrigo Ciríaco para Argentina, Paris, Berlim, Cidade do México, Maputo, Luanda e suas periferias. Também vale lembrar que, não poucas vezes, essas viagens são mediadas por pesquisadores daqueles países, atentos ao tique-taque do mundo, traduzindo suas obras, apresentando-os a esses novos públicos, criando eventos culturais e políticos - promovendo a circulação das ideias e as aproximações entre intelectuais orgânicos das periferias globais.

Além de, na Parte I: A periferia se faz presente (p. 22-94), apresentar algumas dessas questões, de maneira interessante, e debatê-las em perspectiva histórica, Reyes confere também especial atenção a quatro tópicos importantes na discussão sobre a ideia de literatura periférica, na sintomaticamente batizada Parte II: Na contramão (p. 96-219): os usos da memória social como arma política; o emprego da língua, na tensão entre oralidade e a gramática, que encerra uma discussão sobre o poder; o escritor, o intelectual, o ativista político cultural dessa literatura que aparece sob a figura do mediador entre diferentes mundos; e, por fim, o debate sobre as formas da violência e os sentidos que ela assume na composição literária periférica.

No que tange à literatura periférica, os usos políticos da memória coletiva cumprem diferentes funções, seja de conectá-la a formas estéticas ou elementos históricos anteriores ou, ainda, conferir-lhe identidade 
histórica e comunitária: a lembrança de como os periféricos foram parar na periferia, além de criar e funcionar como um testemunho de identidade, tem o papel de não apenas demarcar a diferença e um inimigo de combate mas, também, gerar uma relação afetiva com a perifa, a quebrada, as vielas. Nesse sentido, contra a constante visão da precariedade tem-se a construção sísifica de uma contraimagem. Mas, como nos lembra Reyes, pensando com Albert Camus, acerca do mito, deve-se imaginar que Sísifo tenha sido feliz e esse trabalho criativo não seja inglório ou em vão, capaz de gerar frutos que trafegam da autoestima à construção de uma identidade política e cultural emancipadora.

Seu debate sobre a questão dos usos da língua é um ponto alto do livro. Aqui, o autor extrapola o tema da literatura periférica brasileira para colocá-la em situação com a história da colonização latinoamericana, mormente da América hispânica. Reyes recorda como se dá o processo de dicionarização da língua espanhola e sua função na empresa colonial. O controle do uso da língua é uma forma de dominação de um grupo sobre outro. E sua normatização entre o que é um absolutamente certo e um absolutamente errado constituem-se numa gramática do poder e de dominação.

Ora, as primeiras críticas que os escritores periféricos sempre recebem é a de que escrevam errado e cometem assassinatos em seus idiomas pátrios. Sendo a fala produto do pensamento, subjaz a crítica, raramente explicitada, de que também são incapazes de idear o mundo. De outro lado, os pesquisadores e interessados que os tentam estudar e os respeitar são acusados de legitimar a ignorância, dignificar o erro. Ou, quando há um pouco mais de civilidade na discussão, estudar uma literatura menor (escapando ao sentido conferido a essa expressão por Gilles Deleuze e Félix Guattari) ou uma literatura em sentido lato, sem o $L$ maiúsculo, um relato, um documento social, com algum interesse para as ciências sociais, exclusivamente.

$\mathrm{O}$ autor enfrenta essas questões com muita propriedade, de quem, além de pesquisador, também é escritor e ativista político cultural. E antes que este tópico termine (será que termina algum dia?) demonstra-nos que, nos usos da oralidade, do popular e da linguagem ao rés do chão, do trabalho e do suor, tem-se a construção de um mundo em emancipação. O escritor periférico - não apenas no Brasil -, os ativistas, os moradores das periferias, nesse embate quotidiano, têm a possibilidade de criar os caminhos da sua liberdade e autolegitimação. É muito interessante a 
análise que faz, nesse ponto, da personagem Filomena Da Cabula, da peça homônima e premiada de Allan da Rosa (2006).

Alejandro Reyes recorda também que o intelectual periférico é um sujeito entre dois mundos. E, nesse caso, padece do drama da bifrontalidade, que é o de procurar criar interlocução e inteligibilidade entre as duas margens do rio, correndo o risco de não ser compreendido ou de trair sua mensagem. Em grande medida esse é o drama de todo intelectual insurgente, subalternizado e que busca a emancipação plena, inclusive das armadilhas identitárias que, paradoxalmente, mantém-no na condição subalterna ao passo em que lhe conferem uma identidade política e cultural.

Os dramas da mediação, portanto, colocam ambiguidades constantes aos intelectuais insurgentes, que partem do o quê, para quem, por quê, por quem se escreve até os limites do diálogo, inclusive com seu antagonista histórico e interlocutor a contragosto: o sistema, a mídia, a elite, o centro, a metrópole, os brancos, o Estado, o capitalismo. Na fronteira dos encontros, podem-se entrever tanto traições de projetos originais como habilidade de uso das armas inimigas: o que espera um escritor negro/indígena da periferia ao falar para um público branco no centro do capitalismo global? O que acontece às obras da literatura periférica publicadas por uma grande editora do mercado editorial ou ter suas ações financiadas por um instituto cultural vinculado a um banco? Ou participar de concorrências em editais de fomento cultural do Estado, histórico organismo minguante da periferia e detentor do monopólio da violência legítima, useira e vezeira nas estatísticas policiais?

$\mathrm{O}$ autor nos propõe observar a sociedade brasileira a partir de uma de suas mediações fundantes - e talvez tão constante quanto o patriarcalismo e o favor -, qual seja, a violência simbólica, das relações sociais, internalizadas e reproduzidas quotidianamente.

Enfrenta e escapa, assim, ao debate, muitas vezes judicial, pouco analítico ou fecundo, se a literatura periférica faz ou não apologias da violência. Numa das passagens mais interessantes do livro, ao debater esteticamente o assunto, ele mostra como em pouco menos de 50 anos, da caça de um gato num episódio do filme Cinco vezes favela (1962) e a angústia de um menino, para, de outro lado, o extermínio de um outro felino por outro garoto no livro Cidade de Deus (1997), pode-se observar uma impressionante alteração da sensibilidade social para com o tema da violência. Da mesma forma que uma sociedade que legitima um 
organismo policial (BOPE - RJ) cujo símbolo é uma faca em caveira e ri com as representações de tortura e assassinato desse agente oficial do Estado, num filme, faz pensar quem faz apologia ao quê.

Volte-se, finalmente, ao tema da mediação e amplie-se um pouco a figura do mediador, extrapolando a análise feita sobre os escritores e intelectuais periféricos, para que se pense junto o pesquisador e analista desses temas e seus protagonistas. Alejandro Reyes desde o início do trabalho não tem problema algum em se colocar em primeira pessoa no texto, empregando a língua de maneira rica e pouco usual nas teses e livros acadêmicos, que, por vezes, o colocam em cena, parceiro e aliado dos escritores, ativistas e intelectuais periféricos que analisa. Não se trata de procedimento novo. Impossível não se lembrar da criadora da Coleção Tramas Urbanas, Heloisa Buarque de Hollanda, que com sua tese/livro Impressões de viagem (1981), sobre a literatura marginal dos anos 1970, fez o mesmo, por exemplo.

Contudo, quero pensar o papel do mediador/pesquisador, dos sujeitos que têm feito, nos últimos anos, trabalhos de orientação, iniciação científica, mestrado ou doutorado sobre esses temas ou correlatos. Muitas vezes, também no texto do Alejandro, existe a preocupação de, apesar de solidário, não querer ser normativo, indicar caminhos de como o mundo poderia ser. Mas essa vontade escapa ao controle e ao rigor do autor, porque, evidentemente, o mundo tal como ele é, especialmente depois de ter sido estudado, no mínimo, não é justo para pelo menos $90 \%$ da população mundial. É o que nos demonstra o autor na sua terceira parte, a (In) conclusão.

Apresenta-se um sujeito histórico, amálgama de variadas identidades subalternas, que se corporificou neste início de século, o periférico, e que se encontra numa circunstância de crise capitalista e da produção de excedente humano que não será reincorporado, não é um exército industrial de reserva. É um algo novo, que desafia a história e que se tem de repensar e ser ressignificado, para si e pelos pesquisadores, para estar à altura de suas questões.

Se não adianta criar uma obra periférica sem a ressignificação crítica da visão de mundo que produziu a periferia, também não adianta muito estudar o assunto de maneira asséptica. O mediador/pesquisador acadêmico padece igualmente daquele drama de ser dois, de uma bifrontalidade comunicativa. Angústia não pode ser pensado como conceito próprio às ciências sociais. Mas essa é uma tensão narrativa 
que perpassa as linhas de Vozes dos Porões e de outros trabalhos que tratam do tema. E também dos escritores e intelectuais subalternizados, insurgentes, de modo amplo. E isso instiga a refletir, procurar as formas de ação para ressignificar o mundo, um desafio que se encontra ao final deste livro de Alejandro Reyes, cuja leitura é altamente recomendável.

\section{Referências}

HOLLANDA, Heloisa B. de (1981). Impressões de viagem: CPC, vanguarda e desbunde. 2. ed. São Paulo: Brasiliense.

LINS, Paulo (1997). Cidade de Deus. São Paulo: Companhia das Letras.

NASCIMENTO, Érica Peçanha do (2012). É tudo nosso! Produção cultural na periferia paulistana. Tese (Doutorado em Antropologia) - Universidade de São Paulo, São Paulo.

ROSA, Allan Santos da (2007). Da cabula. São Paulo: Toró.

SCHWARZ, Roberto (2000 [1977]). Ao vencedor as batatas: forma literária e processo social nos inícios do romance brasileiro. 4. ed. São Paulo: Duas Cidades; 34 .

SILVA, Mário Augusto M. da (2013). A descoberta do insólito: literatura negra e literatura periférica no Brasil (1960-2000). Rio de Janeiro: Aeroplano. 